Editorials

\title{
The Timeless Contribution of Rootstocks towards Successful Horticultural Farming: From Ancient Times to the Climate Change Era
}

\author{
Ioannis E. Papadakis \\ Laboratory of Pomology, Department of Crop Science, Agricultural University of Athens, Greece
}

Grafting is a horticultural practice by which living vegetative plant organs (root, stem and/or buds) of either the same genotype or, usually, different genotypes belonging to the same species, genus, subfamily and/or family, are tightly connected to each other to form a double-compound plant. In fact, it is a method of asexual (clonal-vegetative) propagation of plants. The basal part of a grafted plant is called "rootstock" ("stock" or "understock") that usually comprises the root system and a portion of the lower above ground plant stem (trunk). The rest above-ground part of a grafted plant is termed "scion". Following successful grafting, the resulting composite plant continues growth as one individual organism according to its life-span genetic potential (annual, biennial or perennial). Early humans observed non-anthropogenic (natural) grafting in forest natural ecosystems and tried to mimic nature and, thus, applying grafting (artificial grafting) not only in domesticated forest ecosystems, but also to cultivated plants including fruit trees, grape vines, floricultural crops and vegetables. In the writings of the Greek physician, Hippocrates of Kos (460-377 BC), and Greek philosophers, Aristotle (384-322 BC) and Theophrastus (371-287 BC), grafting was clearly reported as a wellestablished agronomical practice at that time period.

From a practical perspective, the existence of words referring to the present usage of the terms "rootstock", "stock" and/or "understock" is inextricably linked with the existence of the grafting per se. In fact, without artificial or natural grafting, there is no "rootstock" and vice versa.

Historically, critical roles of rootstocks have evolved through time periods expanding from years to millennia. This is due to dramatic changes in farming management requirements and/or environmental, climatic and phytopathological conditions existing in the field of horticultural crops -including fruits, vegetables and ornamentals- from the ancient times up to the era of climate change.

For many centuries, grafting was mainly used as a means of non-sexual (asexual) reproduction of plant genotypes which were difficult to root by using other methods of asexual propagation, such as cuttings, suckering, stooling and layering. The aim was then the successful cultivation of genotypes with individual desirable agronomical and horticultural traits by grafting them onto pre-existed wild plants that produced commodities of inferior quality. Although the latter plants were used as rootstocks, their contribution was too specific. They were just used as a background plant, since they had simply provided their root system and a part of their vascular system to the new-composite plants formed after grafting. Through the following years and centuries, macro observations of agronomists and farmers have given motivation to intensive scientific research projects, carried out all over the world, aiming to breed and/or select new superior genotypes for using them as rootstocks.

The second half of the 19th century, the French wine industry was really in panic when the insect phylloxera (Daktulosphaira vitifoliae Fitch) nearly destroyed the grape and wine production. Until nowadays, this insect has never been eradicated or controlled by other chemical or cultural means and still remains a serious problem in susceptible wine/grape-producing regions globally. The ultimate solution remains the use of phylloxera resistant rootstocks, originating from native American Vitis species like V. riparia, V. berlandieri and $V$. rupestris (Mudge et al., 2009). Additionally, from the beginning of the 20th century, the aphid-transmitted Citrus Tristeza Virus (CTV) has destroyed thousand hectares of citrus trees (more than 100 millions) all over the world, grafted on sour orange (Citrus aurantium L.) rootstock, which has been proved to be very susceptible to CTV. In this case, the best solution has also remained the prophylactic grafting of various citrus varieties on CTV resistant rootstocks, such as trifoliate orange (Poncirus trifoliata sp.) and its grapefruit (Citrumelos) or sweet orange (Citranges) hybrids. Before the appearance of the CTV, sour orange had been widely used as a rootstock to protect citrus against harmful effects of Phytophthora spp (Roistacher et al., 2010). Moreover, as a result of the limited availability of arable land, the high demand for off-season vegetables and the intensive production practices with limited crop rotations, vegetables are often cultivated under adverse conditions (Savvas et al., 2010). In fact, the intensive continuous monoculture of vegetables has led to the establishment and exponential growth of many soil- 
borne diseases, like Verticillium spp., Fusarium spp. and bacterial wilts. This resulted in serious damages in plants, lower yields and production of inferior quality commodities. To overcome this problem, in the middle of the 20th century, Japanese and Korean researchers and farmers were the first who succeeded in the large scale production of various commercial cultivars, belonging to Solanaceae and Cucurbitaceae families, grafted on appropriate disease-resistant rootstocks. Today, grafting of vegetables is a widely spread horticultural practice that is commercially exploited in many countries all over the world (Mudge et al., 2009; Lee et al., 2010; Schwarz et al., 2010).

Although biotic factors are usually the main reasons of using rootstocks in fruit, ornamental and vegetable crops, there are many other reasons for grafting commercial varieties on different rootstocks. For example, grafting represents an important means to avoid or reduce yield losses due to salinity stress. The benefits of grafting high-productive genotypes onto salinity-resistant rootstocks include better growth and higher yield, higher photosynthesis, water content, elevated concentrations of osmoprotectants, antioxidants, abscisic acid and polyamines in leaves and lower contents of sodium and/or chloride in various plant parts, compared to un-grafted plants (Colla et al., 2010; Penella et al., 2016). Rootstock can also affect various aspects of plant nutrition under conditions of mineral deficiency or toxicity. Indicatively, the role of the rootstock is critical when citrus trees are cultivated in orchards irrigated with water containing high boron. More specifically, 'Clementine' mandarin and 'Navelina' orange plants grafted on 'sour orange' rootstock proved to be more sensitive to boron excess than those grafted on 'Swingle citrumelo'. This is mainly due to lower absorption of boron from the roots of 'Swingle citrumelo' and to higher boron retention in the stem of this rootstock, resulting in lesser boron accumulation in leaves of the two aforementioned cultivars when they are grafted on 'Swingle citrumelo' (Papadakis et al., 2004a; 2004b).

Besides from the premium contribution of rootstocks in the adaptation of grafted varieties on adverse abiotic and biotic conditions, their effects on different stages of farm management and cultivation practices per se have been well documented. For instance, the use of shading nets is a common, although too expensive, procedure to decrease the impact of high solar irradiance stress during the spring-summer harvesting period, especially in Mediterranean areas. The use of some rootstocks has been reported to be an economically-efficient alternative means to maintain commercial fruit yield and quality under nonshaded greenhouse conditions (Lopez-Marin et al., 2013). Therefore, the overall benefit is at least double, decreasing production costs (there is no need to buy shading nets) and protecting the environment (less manufacture of shading nets). Similarly, rootstock can affect the overall performance of scion, when plants are exposed to suboptimal air and soil temperatures, resulting in either prompt-earlier vegetative and reproductive growth (fruit set, growth, maturation and harvest), or extension of the growing season. The respective earlier and/or delayed harvest, combining with higher yields succeeded over the time together with the production of better quality commodities, result in a significant increase of farmers' net income (Schwarz et al., 2010). Finally, the establishment of high density fruit tree plantings is exclusively based on dwarfing rootstocks which not only induce scion precocity and higher yields per unit of orchard area, but also substantially decrease labor and production costs per each unit of produced fruits (Robinson, 2011).

The beneficial impacts of the rootstocks may also be extended beyond harvest. Some indicative examples are addressed below, although more research has to be carried out in the future for all related issues. Firstly, rootstock can improve the main quality indices of various harvested products, including the overall nutritive value and aromatic substances of horticultural products (Rouphael et al., 2010; Orazem et al., 2011; Krumbein, 2013; Legua et al., 2014). They may also enhance the levels of various particular health-promoting substances (Rouphael et al., 2010; Turhan et al., 2011; Chavez-Mendoza et al., 2013. Krumbein, 2013; Legua et al., 2014; Cardenosa et al., 2015) or decrease those of health hazardous ones (e.g., organic pollutants) (Schwarz et al., 2010). Secondly, postharvest storage and shelf life of fruits and vegetables are also rootstock-dependent (D'Hallewin et al., 1993; Ritenour et al., 2004). Thirdly, the effect of rootstock may also be critical in the processing of fruits and vegetables. For instance, since $\mathrm{pH}$ adjustment is a significant part of the total cost of vinification, the identification of rootstocks that result in lower potassium concentrations and $\mathrm{pH}$ values in grape must and wine is of high interest for the wine industry (Walker and Blackmore, 2012; Bouza et al., 2013), particularly in world's regions producing wine with relatively high values of $\mathrm{pH}$. In the latter case, suitable rootstocks could help in reducing winemaking production cost and improving some key quality attributes of wine.

It is well-known that global warming and the impact to the environment are issues of increasing importance and a subject of international debate, mainly over the last years, attracting the attention of several scientific studies (Landi and Benelli, 2016), including research on new rootstocks. In particular, at the current era of the climate change, breeding and selecting rootstocks with specific traits (e.g., heat, drought, salinity, waterlogging and/or flooding tolerance), due to continuous changing environmental issues, will help in successful growing of fruits and vegetables even in the most affected areas worldwide. As a result of global warming, the accumulated winter chill is continuously decreasing in 
many regions of the world (Baldocchi and Wong, 2008; Atkinson et al., 2013), a fact that may cause serious limitations in the cultivation of temperate-zone deciduous fruit and nut tree species due to incomplete dormancy release. Based on the literature (Ghrab et al., 2014), the role of rootstocks could be vital thanks to their beneficial effects on the scions' buds requirements for chilling units to overcome dormancy. However, more research is needed to evaluate more appropriate rootstock-scion combinations for areas having relatively low chilling hours. Moreover, as the climate continues to be warmer, the frequency, the intensity and the duration of serious precipitation events is expected to increase, enhancing the probability for soil waterlogging/flooding in many areas of the world (Kundzewicz et al., 2014). Selecting and/or creating new rootstocks to resist anaerobic soil conditions are really important challenges for horticultural breeders.

The research on rootstocks is really multidisciplinary, requiring the contribution of different, usually wellseparated, horticultural and agricultural branches. Since 1900s, huge funds have been invested worldwide in breeding, selecting and evaluating genotypes having the proper traits to be used as superior rootstocks. According to an independent assessment commissioned by the Australian Grape and Wine Authority (AGWA), every dollar invested in vine rootstock-associated research generates $\$ 11$ in return to users of rootstocks only across the Australian wine industry (AGWA, 2015).

A superior rootstock enables the genetically composite plant, viz. each one specific rootstock-scion combination, to adapt to a number of different factors including root- and/or shoot-associated both abiotic [e.g., drought, waterlogging, flooding, salinity, mineral toxicity, mineral deficiency, heavy metal toxicity, heat, cold, low chilling units, low soil temperature, low soil oxygen, wet or poorly drained soils, soils with high calcium carbonate content, high or low soil $\mathrm{pH}$ (Papadakis et al., 2004a; 2004b; Colla et al., 2010; Hartmann et al., 2013; Savvas et al., 2010; Ghrab et al., 2014; Castle et al., 2016)] and biotic [e.g., fungal and bacterial pathogens, virus and virioid diseases, insect and nematodes (Mudge et al., 2009; Shokrollah et al., 2009; Roistacher et al., 2010; Louws et al., 2010; Castle et al., 2016)]. Furthermore, rootstock can theoretically affect every characteristic of the scion [e.g., overall plant growth, plant shape, fruit shape, fruit weight, fruit color, fruit firmness, content of phytochemicals in fruits and juices and postharvest storability and shelf life of fresh fruits (Ritenour et al., 2004; Rouphael et al., 2010; Orazem et al., 2011; Turhan et al., 2011; Castle et al., 2016). In applied horticulture, all these factors play a determinant role for the final choice of the best rootstock/s for each one given grove having its own particular characteristics.

Although there are thousands of research papers describing the special effects of various rootstocks on agronomical, phytosanitary, phenotypical, morphological, anatomical, physiological and biochemical aspects of scions, belonging to a wide range of plant species, the implicated mechanisms are still quite obscure and need to be elucidated in the future. Recently, Aloni et al. (2010) and Goldschmidt (2014) reported that long-distance protein, mRNA and small RNA graft-transmissible signals currently emerge as novel mechanisms which regulate nutritional and developmental root/top relations and may play a crucial role in investigating basic processes in rootstock-scion communication. They further noted that available molecular tools (e.g., gene silencing) today are expected to advance our understanding and eventually resolve the long standing grafting mysteries, relating mainly to the interactions of each rootstock-scion combination (Aloni et al., 2010; Goldschmidt, 2014). Apart from that, anatomical, physiological and genetic basis for compatibility between each rootstock-variety combination need to be examined in a wider biological context (Mudge et al., 2009). Undoubtedly, such studies are easier to be carried out with herbaceous vegetables or some plant models, compared to fruit and ornamental perennial trees. The very short biological cycles of vegetables and other species used widely as model plants offer the opportunity to researchers to investigate the effects of rootstocks on all critical vegetative and reproductive growth stages of plants, including studies not only at genetic, but also epigenetic level. In any case, breeding, selecting and testing of new rootstocks with desirable attributes will greatly benefit from the understanding of how exactly the rootstocks can affect the growth and development of scion. However, since the results from several horticultural plants may not be applicable to other species, research on species-specific grafting responses is required. Moreover, given that most of the published papers present the response of grafted plants to only a single stress, in the absence of any other biotic or abiotic one, the question remains whether the concurrent imposition of two or more stresses alters dramatically the specific responses of a rootstock to each stress separately. Towards acquiring a better knowledge concerning the rootstock-scion interactions, every scientific paper about basic and/or applied research on the rootstocks is well-welcome for publication, after rigorous peer review process, to the American Journal of Agricultural and Biological Sciences (AJABS).

Overall, each rootstock is a multi-dynamic horticultural tool functioning as a bridge, i.e., as an artificial Trojan horse, by which a cultivar with important agronomical traits can be ideally cultivated to a farm with too specific unfavorable environmental, phytosanitary and/or cultural management conditions. Actually, the use of appropriate rootstocks increases the tolerance of cultivated varieties under adverse biotic and abiotic conditions. Rootstocks can further affect 
significantly the overall behavior of scions, including specific growth characteristics, yield efficiency and the main quality indices of horticultural products. As a result, the production of quantitatively more and qualitatively better agricultural products and byproducts can be achieved by using suitable rootstocks. From a practical point of view, the choice of the most appropriate rootstock (s), for a given farm, variety and cultural management conditions, is considered as an environmentally friendly and sustainable farming practice lowering the use of agrochemicals (e.g., pesticides, fertilizers) and other costly inputs (e.g., water). It also helps in protecting the environment, the consumers and the farmers, per se, but also in decreasing the production costs and in increasing the overall farm's profitability. Except for the conventional farms, the role of rootstock is undoubtedly vital under conditions of sustainable, integrated and organic, farming. Concluding, the unique value of rootstocks as key factors for the successful cultivation of horticultural crops is unquestionable, rendering them timeless allies for farmers growing vegetables, grape vines and/or fruit trees.

\section{Acknowledgement}

The author would like to thank Prof. I. Therios, Dr. N. Kavroulakis, Dr. G. Doupis and Dr. A. Malandrakis for their valuable and constructive comments and suggestions that contributed to improve the quality of the current editorial.

\section{References}

AGWA, 2015. Rootstock research: Increasing productivity and profitability. Australian Grape and Wine Authority.

Aloni, B., R. Cohen, L. Karni, H. Aktas and M. Edelstein, 2010. Hormonal signaling in rootstockscion interactions. Sci. Hortic., 127: 119-126. DOI: $10.1016 /$ j.scienta.2010.09.003

Atkinson, C.J., R.M. Brennan and H.G. Jones, 2013. Declining chilling and its impact on temperate perennial crops. Environ. Exp. Bot., 91: 48-62. DOI: $10.1016 /$ j.envexpbot.2013.02.004

Baldocchi, D. and S. Wong, 2008. Accumulated winter chill is decreasing in the fruit growing regions of California. Clim. Change, 87: 153-156. DOI: $10.1007 / \mathrm{s} 10584-007-9367-8$

Bouza, D., K. Biniari and M.N. Stavrakakis, 2013. Effect of potassium fertilization on capacity and grape yield of the vines and on some characters of the must of the grape cultivar Agiorgitiko (Vitis vinifera L.) under vineyard conditions. Proceedings of the 3rd International Symposium Ampelos, (ISA' 13), Santorini, Greece, pp: 1-16.
Cardenosa, V., L. Barros, J.C.M. Barreira, F. Arenas and J.M. Moreno-Rojas et al., 2015. Different Citrus rootstocks present high dissimilarities in their antioxidant activity and vitamins content according to the ripening stage. J. Plant Physiol., 174: 124-130. DOI: $10.1016 /$ j.jplph.2014.10.013

Castle, W.S., K.D. Bowman, J.W. Grosser, S.H. Futch and J.H. Graham, 2016. Florida Citrus Rootstock Selection Guide. 3rd Edn., UF/IFAS Extension Service, University of Florida, pp: 3.

Chavez-Mendoza, C., E. Sanchez, E. Carvajal-Millan, E. Munoz-Marquez and A. Guevara-Aguilar, 2013. Characterization of the nutraceutical quality and antioxidant activity in Bell pepper in response to grafting. Molecules, 18: 15689-15703. DOI: $10.3390 /$ molecules 181215689

Colla, G., Y. Rouphael, C. Leonardi and Z. Bie, 2010. Role of grafting in vegetable crops grown under saline conditions. Sci. Hortic., 127: 147-155.

DOI: $10.1016 /$ j.scienta.2010.08.004

D'Hallewin, G., D. Mura, A. Piga, M. Pala and G. Lovicu, 1993. Rootstock effects on postharvest physiological and pathological behaviour of 'Avana' mandarin. Acta Hort., 368: 395-402. DOI: 10.17660/ActaHortic.1994.368.49

Ghrab, M., M. Ben Mimoun, M.M. Masmoudi and N. Ben Mechlia, 2014. Chilling trends in a warm production area and their impact on flowering and fruiting of peach trees. Sci. Hortic., 178: 87-94. DOI: $10.1016 /$ j.scienta.2014.08.008

Goldschmidt, E.E., 2014. Plant grafting: New mechanisms, evolutionary implications. Front. Plant Sci., 5: 1-9. DOI: 10.3389/fpls.2014.00727

Hartmann, H.T., D.E. Kester, F.T. Davies and R.L. Geneve, 2013. Hartmann and Kester's Plant Propagation: Principles and Practices. 8th Edn., Pearson Education Limited, Harlow, ISBN-10: 1292034130, pp: 928.

Krumbein, A., 2013. Grafting: A possibility to enhance health-promoting and flavour compounds in tomato fruits of shaded plants? Sci. Hortic., 149: 97-107. DOI: $10.1016 /$ j.scienta.2012.09.003

Kundzewicz, Z.W., S. Kanae, S.I. Seneviratne, J. Handmer and N. Nicholls et al., 2014. Flood risk and climate change: Global and regional perspectives. Hydrol. Sci. J., 59: 1-28.

DOI: $10.1080 / 02626667.2013 .857411$

Landi, M. and G. Benelli, 2016. Protecting crop species from biotic and abiotic constraints in the era of global change: Are we ready for this challenge? Am. J. Agric. Biol. Sci., 11: 51-53. DOI: 10.3844/ajabssp.2016.51.53

Lee, J.M., C. Kubota, S.J. Tsao, Z. Bie and P.H. Echevarria et al., 2010. Current status of vegetable grafting: Diffusion, grafting techniques, automation. Sci. Hortic., 127: 93-105.

DOI: $10.1016 /$ j.scienta.2010.08.003 
Legua, P., J.B. Forner, F. Hernandez and M.A. FornerGiner, 2014. Totalphenolics, organic acids, sugars and antioxidant activity of mandarin (Citrus clementina Hort. ex Tan.): Variation from rootstock. Sci. Hortic., 174: 60-64.

DOI: $10.1016 /$ j.scienta.2014.05.004

Lopez-Marin, J., A. Gonzalez, F. Perez-Alfocea, C. Egea-Gilabert and J.A. Fernandez, 2013. Grafting is an efficient alternative to shading screens to alleviate thermal stress in greenhouse-grown sweet pepper. Sci. Hortic., 149: 39-46.

DOI: $10.1016 /$ j.scienta.2012.02.034

Louws, F.J., C.L. Rivard and C. Kubota, 2010. Grafting fruiting vegetables to manage soilborne pathogens, foliar pathogens, arthropods and weeds. Sci. Hortic., 127: 127-146. DOI: $10.1016 /$ j.scienta.2010.09.023

Mudge, K., J. Janick, S. Scofield and E.E. Goldschmidt, 2009. A history of grafting. Hortic. Rev., 35: 437-493. DOI: 10.1002/9780470593776.ch9

Orazem, P., F. Stampar and M. Hudina, 2011. Fruit quality of redhaven and royal glory peach cultivars on seven different rootstocks. J. Agric. Food Chem., 59: 9394-9401. DOI: 10.1021/jf2009588

Papadakis, I.E., K.N. Dimassi, A.M. Bosabalidis, I.N. Therios and A. Patakas et al., 2004a. Effects of B excess on some physiological and anatomical parameters of 'Navelina' orange plants grafted on two rootstocks. Environ. Exp. Bot., 51: 247-257. DOI: 10.1016/j.envexpbot.2003.11.004

Papadakis, I.E., K.N. Dimassi, A.M. Bosabalidis, I.N. Therios and A. Patakas et al., 2004b. Boron toxicity in 'Clementine' mandarin plants grafted on two rootstocks. Plant Sci., 166: 539-547. DOI: 10.1016/j.plantsci.2003.10.027

Penella, C., M. Landi, L. Guidi, S.G. Nebauer and E. Pellegrini et al., 2016. Salt-tolerant rootstock increases yield of pepper under salinity through maintenance of photosynthetic performance and sinks strength. J. Plant Physiol., 193: 1-11. DOI: $10.1016 /$ j.jplph.2016.02.007
Ritenour, M.A., H. Dou, K.D. Bowman, B.J. Boman and E. Stover et al., 2004. Effect of rootstock on stemend rind breakdown and decay of fresh citrus. Hort Technol., 14: 315-319.

Robinson, T., 2011.Advances in apple culture worldwide. Rev. Bras. Frutic., 33: 37-47. DOI: $10.1590 / \mathrm{S} 0100-29452011000500006$

Roistacher, C.N., J.V. da Graca and G.W. Muller, 2010. Cross protection against Citrus tristeza virus-a review. Proceedings of the 17 th Conference of the International Organization of Citrus Virologists, (OCV' 10), Adana, Turkey, pp: 1-27.

Rouphael, Y., D. Schwarz, A. Krumbein and G. Colla, 2010. Impact of grafting on product quality of fruit vegetables. Sci. Hortic., 127: 172-179. DOI: $10.1016 /$ j.scienta.2010.09.001

Savvas, D., G. Colla, Y. Rouphael and D. Schwarz, 2010. Amelioration of heavy metal and nutrient stress in fruit vegetables by grafting. Sci. Hortic., 127: 156-161. DOI: 10.1016/j.scienta.2010.09.011

Schwarz, D., Y. Rouphael, G. Colla and J.H. Venema, 2010. Grafting as a tool to improve tolerance of vegetables to abiotic stresses: Thermal stress, water stress and organic pollutants. Sci. Hortic., 127: 162-171. DOI: 10.1016/j.scienta.2010.09.016

Shokrollah, H., T.L. Abdullah, K. Sijam, S.N.A. Abdullah and N.A.P. Abdullah, 2009. Differential reaction of citrus species in Malaysia to huanglongbing (HLB) disease using grafting method. Am. J. Agric. Biol. Sci., 4: 32-38. DOI: 10.3844/ajabssp.2009.32.38

Turhan, A., N. Ozmen, M.S. Serbeci and V. Seniz, 2011. Effects of grafting on different rootstocks on tomato fruit yield and quality. Hort. Sci., 38: 142-149.

Walker, R.R. and D.H. Blackmore, 2012. Potassium concentration and $\mathrm{pH}$ inter-relationships in grape juice and wine of Chardonnay and Shiraz from a range of rootstocks in different environments. Aust. J. Grape Wine Res., 18: 183-193. DOI: $10.1111 /$ j.1755-0238.2012.00189.x 